\title{
O FETICHISMO DA MERCADORIA NA SOCIEDADE DE OBSOLESCÊNCIA PROGRAMADA
}

\section{ARTIGO ORIGINAL}

ARAÚJO, Gizelda Rodrigues de ${ }^{1}$

MARQUES, Edmilson ${ }^{2}$

ARAÚJO, Gizelda Rodrigues de. MARQUES, Edmilson. O fetichismo da mercadoria na sociedade de obsolescência programada. Revista Científica Multidisciplinar Núcleo do Conhecimento. Ano 05, Ed. 11, Vol. 10, pp. 146-154. Novembro de 2020. ISSN: 2448-0959, Link de acesso:https://www.nucleodoconhecimento.com.br/educacao/obsolescenciaprogramada

\section{RESUMO}

O referido trabalho faz uma abordagem sobre o fetichismo da mercadoria de Marx, trazendo à tona alguns exemplos que remetem ao valor de uso e valor de troca e faz

${ }^{1}$ Pós graduação em Educação em Gestão ambiental (2011)-Faculdade Serra da Mesa- FASEM - Uruaçu-Go; Pós- graduação em Biologia (2005) - Universidade Federal de Lavras- UFLA; Pós- graduação em Métodos e Técnicas de ensino (2003) - Universidade Salgado de Oliveira- UNIVERSO; Pós- graduanda em Direito Civil (2020) - Pontifica Universidade Católica - PUC - Minas; Graduação em Pedagogia (2001) - Universidade Estadual de Goiás - UEG - Campus Uruaçu; Graduação em Licenciatura em Biologia (2004) - Universidade Estadual de Goiás - UEG Campus Porangatu; Graduação em Licenciatura em Física (2012) - Universidade Federal de Goiás - UFG; Graduanda em Direito (2020) - Universidade Estadual de Goiás - UEG campus de Uruaçu.

2 Orientador. Doutorado em História. Mestrado em História. Especialização em Ciência Política. Graduação em História. 
uma reflexão ao advento da obsolescência programada enfocando a volatilidade com que o fascínio da mercadoria desapareça e pontuar que o padrão de consumo transformou-se numa forma de afirmação social e consequentemente o consumismo representa um pilar importante para o capitalismo. Para tanto objetiva entender sobre o fetichismo da mercadoria em consonância com a obsolescência programada da sociedade atual. Trata-se de uma pesquisa bibliográfica de cunho exploratório e para tanto contou-se com a contribuição dos estudos de Marx em seu livro O Capital, especificamente na parte que trata sobre a Mercadoria, Bauman. No livro Modernidade Líquida, onde aborda sobre a fluidez dos objetos e do descarte da mercadoria e Netto que ressalta sobre trabalho, sociedade e valor.

Palavras-Chave: Fetichismo da mercadoria, obsolescência programada, modernidade líquida.

\section{INTRODUÇÃO}

Vivemos em uma sociedade dita pós-moderna, onde o consumismo impera, nos tornando alienados e ao mesmo tempo endividados. Um produto que adquirimos hoje, em breve será considerado démodé[3], em virtude da necessidade incontrolável de se trocar com frequência a mercadoria que há pouco adquirimos.

A partir da Revolução industrial, o modo de vida capitalista extrapolou de tal forma que a sociedade passou a valorar mais o ter do que o ser. Ser consumista era uma forma de se firmar socialmente. Desta forma, o consumismo torna-se essencial para a manutenção do capitalismo vigente.

Esse consumismo exacerbado teve a sua explosão a partir do ano de 1928, quando foi publicado numa revista influente dos EUA, uma frase que mudou todo perfil da sociedade: "Um artigo que não se desgasta é uma tragédia para os negócios"[4].

A partir de então, as mercadorias que eram duráveis, que eram produzidas para durar a vida toda, agora em nome do capitalismo, tiveram uma redução em sua vida útil são descartáveis e tendo um tempo de vida programada, obrigam o consumidor a se desfazer dessa mercadoria em um tempo menor. 
Entende-se com isso, que se trata de uma "armadilha[5]" do sistema capitalista, o qual percebendo que uma mercadoria que tinha uma durabilidade maior demorava muito mais tempo para ser trocada e com isso estagnava a circulação de mercadorias e consequentemente do capital. Era prejuízo, pois a dinamicidade era muito lenta. Uma vez diminuindo a vida útil do produto, o indivíduo troca com mais frequência, aumentando assim a dinâmica do capital.

Zygmunt Bauman (2008), chamou essa relação de consumo, de obsolescência programada, isto é, a redução intencional de uma mercadoria feita pelo produtor ou fabricante, a fim de obrigar o consumidor a se desfazer do modelo "antigo" e comprar um novo modelo. O consumir tem provocado um efeito negativo nas relações pessoais, no sentido de que o desejo de consumir tudo, propicia o distanciamento entre as pessoas e até consiga mesmas, visto que, ao consumir muito, muitas vezes ficam endividadas e os conflitos no trabalho começam a surgir, causando angústia e até depressão.

\section{PROCEDIMENTOS METODOLÓGICOS / METODOLOGIA}

Trata-se de uma pesquisa bibliográfica, visto que foi a partir do levantamento de referências teóricas, publicadas por meios escrito e eletrônico, como livros, artigos científicos e páginas de web sites que se recolheu informações ou conhecimentos prévios sobre o problema do qual se procura uma resposta.

Segundo Lakatos e Marconi (2003), este tipo de pesquisa não é mera repetição do que já foi dito ou escrito sobre certo assunto, mas propicia um exame de um tema sob novo enfoque ou abordagem, chegando a conclusões inovadoras.

Quanto ao objetivo, trata-se de uma pesquisa exploratória, pois de acordo com Gil (2007), este tipo de pesquisa tem como objetivo proporcionar maior familiaridade com o problema, com vistas a torná-lo mais explícito ou a construir hipóteses.

\section{DESENVOLVIMENTO}


O mundo já passou por várias revoluções sociais e ao longo da história pode se observar que o modo de produção foi diversificando à medida que o homem foi aumentando suas necessidades. No início a produção de bens dependia unicamente da natureza (caça, pesca, frutos), mas à medida que o homem descobriu novas técnicas de produzir seu alimento ou seu vestuário, surgiu uma nova sociedade. $\mathrm{O}$ homem então, passa a transformar matérias naturais em produtos que atendem às suas necessidades, através de atividades a que denominamos trabalho.

Netto (2006), sublinha que as atividades que atendem a necessidades de sobrevivência são generalizadas entre espécies animais, exemplificando o caso do João - de- barro e da abelha em que ambos realizam suas atividades porque já haviam sido programados numa relação natural e o meio ambiente.

Entretanto, entre o homem e a natureza não ocorre essa programação, visto que o homem tem uma forma de trabalho que pertence exclusivamente a ele.

Uma aranha executa operações semelhantes à de um tecelão e a abelha envergonha mais de um arquiteto humano com a construção dos favos de sua colmeia. Mas o que distingue, de antemão, o pior arquiteto da melhor abelha, é que ele construiu o favo em sua cabeça, antes de construí-lo em cera.[...] ele não apenas efetua uma transformação da forma da matéria natural, realiza, ao mesmo tempo, na matéria natural, o seu objetivo.(MARX, 1983, apud NETTO, 2006 ,p. 31).

Possuidor dessa capacidade de planejamento, o homem produz bens que são valores de uso - a mercadoria, a qual vem satisfazer suas necessidades humanas (sejam aquelas que inventamos, que não tem muita necessidade ou aquelas que precisamos para sobreviver). Porém, vale ressaltar que, quando essa mercadoria é produzida apenas para o uso e não é reproduzida para a troca, isto é, ela não tem o intuito de ser vendida, comercializada ou consumida, ela não se constitui em uma mercadoria, é apenas um valor de uso.

Para Marx (1983) todas as mercadorias têm duas características: O valor de uso e o valor de troca. Sendo que o valor de uso está sempre relacionado às características físicas da mercadoria. Já o valor de troca está relacionado a proporção da qual essa mercadoria pode ser trocada numa relação social. O valor da troca é sempre muito 
flutuante porque depende do interesse do indivíduo e não dá para definir pelas características.

Dessa forma entende-se que a mercadoria é:

A mercadoria é, antes de tudo, um objeto externo, uma coisa que, por meio de suas propriedades, satisfaz necessidades humanas de um tipo qualquer. A natureza dessas necessidades - se, por exemplo, elas provêm do estômago ou da imaginação - não altera em nada a questão. (MARX, 2005 p.157)

Marx (2005), chama a atenção ainda para o fato dessa mercadoria ser produzida hoje de forma totalmente fragmentada, onde cada indivíduo faz uma parte do trabalho até formar a mercadoria.

O grande problema gerado por este tipo de produção, ainda segundo Marx (2005), é o fato do trabalhador não se reconhecer no produto que faz. E isto ocorre porque agora ele está alheio a sua mercadoria, visto que, antes o indivíduo produzia tudo, desde a base até o acabamento de uma mercadoria (planejava, criava, definia o tipo de material, desenhava e findava a obra). Tudo era produzido por uma só pessoa.

$\mathrm{Na}$ contemporaneidade, mediante as empresas flexibilizadas, cada um faz uma parte da mercadoria para agilizar o processo, porque tempo é dinheiro. Isso contribui para o fato do trabalhador não se reconhecer no seu produto final, causando estranheza quando se depara com uma mercadoria " $X$ " em um supermercado, por exemplo, ele não pensa que aquela mercadoria só existe por obra de seu trabalho. Ele não se lembra que ele é o único capaz de produzir valor - o trabalho dele é quem produz valor e não o contrário.

$\mathrm{Na}$ expectativa de Marx (2005), quando um indivíduo busca consumir a mercadoria "X" (Um iphone XS Max apple), ele quer possuir porque ela agrega algum status, alguma característica que vai dar para aquele individuo uma valorização social. Esse encanto e deslumbre que a mercadoria causa no individuo, Marx chama de "fetiche[6]" da mercadoria. 
Na nossa imaginação alienante, sempre vai haver preferência a um tipo de mercadoria em relação a outra mesmo as duas tendo o mesmo valor de uso, porém só uma delas dá o status que o indivíduo quer. Remetendo ao exemplo do celular: Se numa vitrine exibe um iphone SX Max Apple e na outra vitrine, quase escondido, está um celular da LG wireless FM- todos dois com o mesmo valor de uso (fazer ligações), só que o primeiro é mil por cento mais caro que o segundo.

Mas, se as duas mercadorias têm o mesmo valor de uso, porque então, uma tem mais valor do que a outra? O que define o seu preço? O que define o seu preço é o tempo necessário para produção dessa mercadoria, ou seja, é o trabalho humano empregado nessas mercadorias. Isso é o que define o valor real. Agora o que faz uma ter um valor exorbitante em relação a outra, é a questão do fetiche, é a questão de valorizar o indivíduo. Então para valorizar o indivíduo, essa mercadoria vai ser cada vez mais cara.

Assim, podemos perceber que:

O valor de uma mercadoria está para o valor de qualquer outra mercadoria como o tempo necessário de uma está para o tempo necessário de trabalho para a produção da outra.[...] Quanto maior é a força produtiva do trabalho, menor é o tempo de trabalho requerido para a produção de um artigo, menor a massa de trabalho nele cristalizada e menor seu valor. Inversamente, quanto menor a força produtiva do trabalho, maior o tempo de trabalho necessário para a produção de um artigo e maior o seu valor. (MARX, 2005, p.164)

Nota-se com isso que a mercadoria quando finalizada, isto é, quando fica pronta, não mantinha o seu valor real de venda, que segundo Marx (2005), esse valor é determinado pela quantidade de trabalho materializado no produto e no entanto, essa mercadoria adquiria uma valoração de venda irreal, infundada, como se não fosse fruto do trabalho humano e nem pudesse ser mensurado, o que ele queria demonstrar com isto é que a mercadoria parecia perder sua relação com o trabalho e ganhar vida própria.

Sobre isto, Marx (2005) diz que, à primeira vista, uma mercadoria parece uma coisa trivial e que se compreende por si mesma, entretanto a partir do momento que surge 
como mercadoria, como valor de troca, as coisas mudam de figura- transforma-se numa coisa mística, palpável e impalpável.

Todos nós, seres humanos[7], durante a nossa história de vida, tem determinadas coisas que colocamos no topo do que é mais importante - isto é valorar. Como exemplo podemos citar os jovens de periferia que às vezes deixam de se alimentar bem, subtraindo algumas refeições, se endividam ou até fazem coisas ilícitas para poderem possuir um celular da moda, ou algo que esteja em voga. Para eles, um celular é tudo. Dá status e sempre que sai um novo modelo, fazem de tudo para adquiri-lo. Para eles não importa se a casa onde moram é ruim, se moram no pior bairro da cidade, se comem mal, se estudam em uma escola sem qualidade, pois o que os deixa fora de si, enfeitiçados, é um celular da moda. Então, essas pessoas valoram essas mercadorias como algo supremo e fazem qualquer coisa para obtê-las.

Marx (1983), complementa[8] esse pensamento dizendo que na sociedade capitalista a burguesia cria um aspecto fundamental para manutenção de seus privilégios, então essa burguesia vai fazer com que seus valores também sejam dominantes nessa sociedade, utilizando-se da ideologia para mascarar as relações de explorações existentes., passando esses valores para as pessoas, a fim de se manter no processo de produção e venda de mercadorias.

A burguesia valora tanto a mercadoria que ela se torna um valor supremo, a coisa mais importante. Entretanto, para que o valor desta mercadoria seja aceito pelos indivíduos, esse valor precisa ser reproduzido cotidianamente. Nesta fase entra o marketing, estratégias de vendas e armadilhas, fazendo com que os indivíduos valorizem mais a mercadoria do que o ser humano. Com isso, o ser humano acaba dando lugar a mercadoria, se coisificando. Há uma inversão no processo, onde o criador passa a ser dominado pela criação. - O fetiche da mercadoria.

A mercadoria é misteriosa[9] simplesmente por encobrir as características sociais do próprio trabalho dos homens, apresentando-as como características materiais e propriedades sociais inerentes aos produtos do trabalho; por ocultar, portanto, a relação social entre os trabalhos individuais dos produtores e o trabalho total, ao refleti-la como relação social existente, à margem deles, entre os produtos de seu 
próprio trabalho se tornando mercadorias(...) Uma relação social definida, estabelecida entre os homens, assume a forma fantasmagórica de uma relação entre coisas(...) Chamo a isto de fetichismo, que está sempre grudado aos produtos do trabalho, quando são gerados como mercadorias. É inseparável da produção de mercadorias (MARX, 1983, p.81).

Entende-se com isso que o fetichismo da mercadoria é a percepção das relações sociais envolvidas na produção, não como relações entre os indivíduos, mas como as relações econômicas entre o dinheiro e as commodities negociadas no mercado. Sendo assim, o fetichismo da mercadoria transforma os aspectos subjetivos em aspectos objetivos.

Mediante os conceitos abordados sobre mercadoria e fetichismo de Marx, vale ressaltar a obra de Bauman (2008) a fim de se trabalhar o consumo sob outra perspectiva.

Uma vez o fetichismo da mercadoria, visto como um processo que encobre e máscara as relações efetivas entre homens em favor da relação entre coisas, Bauman (2008) acrescenta que na sociedade de consumidores a dinâmica de mascaramento se dá pelo viés da subjetividade.

Neste contexto, Bauman (2008) afirma que a subjetividade está altamente associada à transformação dos indivíduos em mercadoria.

Na sociedade de consumidores, ninguém pode se tornar sujeito sem primeiro virar mercadoria, e ninguém pode manter segura sua subjetividade sem reanimar, ressuscitar e recarregar de maneira perpétua as capacidades esperadas e exigidas de uma mercadoria vendável (BAUMAN, 2008, p.20).

Entende-se com isso que o padrão de consumo se transformou em forma de afirmação social, em integração de determinados grupos na sociedade. Dessa forma, o consumismo representa um pilar importante para o capitalismo. E para manter o ritmo avançado de produção e lucro, alimenta-se um sistema manipulador onde a obsolescência dos produtos são motivadas pela mídia convincente. 
As propagandas recheadas de ideologias inculcam nos indivíduos um desejo incontrolável de possuir determinado bem e não sossegam até comprá-lo. Porém esse desejo de posse, esse amor desmedido por determinada mercadoria, logo passa em virtude de ser lançado no mercado outra mercadoria cujas características enchem os olhos, oferecendo mil e uma vantagens. E, assim, o consumidor moderno, descarta seu "antigo objeto" (Com seis meses ou um ano no máximo), e compra a novidade.

E nesse sentido, Bauman (2001), vem nos dizer que:

Pode-se notar a grande importância do consumo na caracterização da "modernidade liquida". Ė por meio dele que aos indivíduos são construídos e transformados constantemente, tornando as identidades individuais passageiras. [...] A "sociedade de consumidores" estimula uma estratégia existencial consumista e rejeita outras opções culturais alternativas[...] (BAUMAN, 2001).

O mundo construído de objetos duráveis foi substituído pelo de produtos disponíveis projetados para imediata obsolescência, ou seja, produtos que já compramos programados para com data marcada para apresentar defeitos. Nesse sentido, pensando no fascínio exercido pela mercadoria e na volatilidade dessa pósmodernidade, ou modernidade líquida, percebe-se que as identidades podem ser adotadas e descartadas como uma troca de roupa.

As mercadorias se tornam obsoletas em um tempo muito curto, e dessa forma os objetos, enquanto objetos de consumo, perdem a sedução logo que são consumidos.

Estamos vivendo uma modernidade líquida, onde tudo flui levemente, tudo é descartável e parece perder seu valor. Diante disso, indago: Esse desapego, essa leviandade com que as coisas estão sendo tratadas, terá implicância em seu valor, em seu preço? A força de trabalho agregado a mercadoria terá menos valor nessa modernidade líquida?

\section{CONSIDERAÇÕES FINAIS}

O fetichismo da mercadoria se traduz em um poder de sedução que a mercadoria exerce sobre os indivíduos, chegando a ocupar o lugar dele. Essa inversão de papéis 
ocorre devido a valoração que ocorre com o consumo da mercadoria, fazendo com que seu criador nem se reconheça mais no produto, tornando-se a coisa. Marx (2008) chamou isso de coisificação: a criação toma o lugar do criador.

Numa outra perspectiva, Bauman (2001) sublinha sobre o consumo exacerbado, sobre a liquidez que derrete tudo em volta, tornando coisas e indivíduos volúveis, descartáveis numa dinâmica de consumismo onde a promessa do "novo" traz felicidade e o descarte do "velho" um vazio que deve ser preenchido por mais consumo.

Para manter este ritmo avançado de produção e lucro, o modelo capitalista adota um sistema manipulador e alienante, utilizando-se da obsolescência programada dos produtos, onde tudo que se consome, perde seu valor a curto prazo.

\section{REFERÊNCIAS}

BAUMAN, Zygmunt. Modernidade líquida. Rio de Janeiro. Editora Zahar, 2001.

BAUMAN, Zygmunt. Vida para o consumo. Rio de Janeio. Ed. Zahar, 2008.

MARX, Karl. O Capital: Mercadoria. São Paulo: Centauro Editora, 2005.

MARX, Karl. O Capital: Crítica da economia política. São Paulo: Nova cultua, 1983.

MEUCCI, Isabella Duarte Pinto. Revista sem aspas. Disponível em: https://periodicos.fclar.unesp.br/semaspas/article/view/69. Acessado em 03/12/18

NETTO, José Paulo e BRAZ, Marcelo. Economia Política- Uma introdução à crítica. Vol. I. S. Paulo. Ed. Cortez, 2006.

\section{APÊNDICE DE RODAPÉ}

[3] Palavra francesa que significa fora de moda. Não está mais na moda.

${ }^{[4]}$ http://revistapontocom.org.br/materias/obsolescencia-planejada 
[5] armadilha no sentido de estratégia

[6] Fetiche: objeto que se atribui poder sobrenatural ou mágico e se presta culto.

[7] Áudio do professor Edmilson Marques.

[8] Áudio do professor Edmilson Marques

[9] https://cafecomsociologia.com/para-entender-de-uma-vez-por-todas-o/acessado em 02/12/2018-Citação de Marx,1983.81

Enviado: Junho, 2020.

Aprovado: Novembro, 2020. 